\title{
Design and Control of a PM Brushless Hybrid Generator for Wind Power Application
}

\author{
K. T. Chau ${ }^{1}$, Y. B. Li ${ }^{2}$, J. Z. Jiang ${ }^{2}$, and Shuangxia Niu ${ }^{1}$ \\ ${ }^{1}$ Department of Electrical and Electronic Engineering, The University of Hong Kong, Hong Kong, China \\ ${ }^{2}$ Department of Automation, Shanghai University, Shanghai 200072, China
}

In this paper, a new permanent magnet (PM) brushless hybrid machine is proposed and implemented for wind power generation. The originality is that a small de field winding and an extra air-bridge are incorporated in the machine so that the air-gap flux can be effectively strengthened or weakened to online keep the output voltage constant throughout the whole wind speed range. The characteristics of flux linkage and no-load electromotive force (EMF) are analyzed by using the finite element method (FEM), and these results agree well with those from magnetic circuit analysis. Experimental results also verify that the proposed machine can produce a constant output voltage over a wide wind speed range.

Index Terms-Finite element method (FEM), flux regulation, permanent magnet machine, wind power generation.

\section{INTRODUCTION}

D UE TO HIGH efficiency and high-power density, permanent magnet (PM) brushless generators are becoming attractive for wind power application. By incorporating the merits of both PM brushless and switched reluctance machines, the doubly salient PM generator has also been proposed for this application [1]. However, the problem of uncontrollable flux is still unsolved, which results in highly variable output voltage when subject to large variations in wind speeds. Recently, the concept of PM brushless hybrid motors has been introduced for electric vehicles [2], [3]. By employing both PM and field winding excitations, the PM brushless hybrid motor can effectively perform flux weakening, and hence, significantly extend the constant-power operating range.

In this paper, the concept of PM brushless hybrid motors is newly extended to wind power generation. Increasingly, the air-gap flux is not only weakened but also strengthened in such a way that the proposed PM brushless hybrid generator can provide constant output voltage under a wide range of wind speed. Both magnetic circuit modeling and finite element analysis will be conducted. A prototype, which is specially designed for a standalone low-voltage power system [4], will be built for experimental verification. Compared with the stator doubly fed doubly salient (SDFDS)-PM brushless machine proposed in [2], this machine has a unique structure which contributes to the more easily mechanical manufacturing and magnet fixing.

\section{Design AND ANALysis}

\section{A. Machine Configuration}

The structure of the proposed PM brushless generator is shown in Fig. 1(a). In the stator, besides the three-phase armature windings, there is a dc field winding in series with each PM. The field winding serves to regulate the PM flux, hence,

Digital Object Identifier 10.1109/TMAG.2006.879436

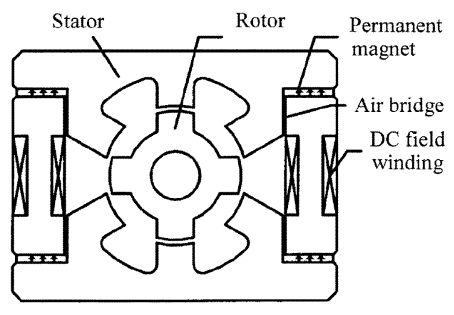

(a)

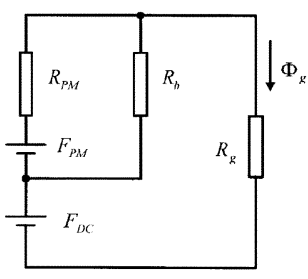

(b)
Fig. 1. Proposed PM brushless hybrid generator. (a) Structure. (b) Magnetic circuit.

offering either flux weakening or flux strengthening. Also, there is an extra air bridge in shunt with each PM. If the field winding magnetomotive force (MMF) reinforces the PM MMF, the air bridge will amplify the effect of flux strengthening. On the other hand, if the field winding MMF is opposite to the PM MMF, it will increase the PM flux leakage, hence, amplifying the effect of flux weakening. As a result, with a proper design of the air-bridge width, a wide flux regulating range can be obtained by using a small dc field excitation. The rotor has neither PMs nor field windings, hence, offering high mechanical integrity for large variations in wind speeds.

\section{B. Magnetic Circuit Analysis}

Fig. 1(b) shows the equivalent magnetic circuit of the proposed machine, where $F_{\mathrm{dc}}$ is the dc field winding MMF, $F_{\mathrm{PM}}$ is the PM MMF, $R_{\mathrm{PM}}$ is the PM reluctance, $R_{b}$ is the air-bridge reluctance, and $R_{g}$ is the air-gap reluctance. From this model, the air-gap flux $\Phi_{g}$ can be expressed as

$$
\Phi_{g}=\frac{F_{\mathrm{dc}}\left(R_{b}+R_{\mathrm{PM}}\right)+F_{\mathrm{PM}} R_{b}}{R_{b} R_{g}+R_{\mathrm{PM}} R_{g}+R_{b} R_{\mathrm{PM}}} .
$$

When $F_{\mathrm{dc}}=0$, the corresponding air-gap flux is given by

$$
\Phi_{g 0}=\frac{F_{\mathrm{PM}}}{R_{g}+\left(R_{\mathrm{PM}} / R_{b}\right) R_{g}+R_{\mathrm{PM}}} .
$$


TABLE I

SELECTION OF RELUCTANCE RATIO

\begin{tabular}{ccc}
\hline$\left(R_{P M} / R_{b}\right)$ & $\left(F_{D C+} / F_{P M}\right)$ & $\left(F_{D C-} / F_{P M}\right)$ \\
\hline 4 & $1 / 5$ & $1 / 10$ \\
3 & $1 / 4$ & $1 / 8$ \\
2 & $1 / 3$ & $1 / 6$ \\
1 & $1 / 2$ & $1 / 4$ \\
$1 / 2$ & $2 / 3$ & $1 / 3$ \\
$1 / 3$ & $3 / 4$ & $3 / 8$ \\
\hline
\end{tabular}

Similarly, the air-gap fluxes $\Phi_{g+}$ and $\Phi_{g-}$ at $F_{\mathrm{dc}+}\left(F_{\mathrm{dc}}>0\right)$ and $F_{\mathrm{dc}-}\left(F_{\mathrm{dc}}<0\right)$, respectively, can be derived. Hence, it yields

and

$$
\left(\frac{F_{\mathrm{dc}+}}{F_{\mathrm{PM}}}\right)=\frac{\left(\Phi_{g+} / \Phi_{g 0}\right)-1}{\left(R_{\mathrm{PM}} / R_{b}\right)+1}
$$

$$
\left(\frac{F_{\mathrm{dc}-}}{F_{\mathrm{PM}}}\right)=\frac{1-\left(\Phi_{g-} / \Phi_{g 0}\right)}{\left(R_{\mathrm{PM}} / R_{b}\right)+1} .
$$

From (3), it can be shown that the magnitude of dc field $\mathrm{MMF}$ is a function of the reluctance ratio $\left(R_{\mathrm{PM}} / R_{b}\right)$. For the proposed generator, a quadruple change of $\Phi_{g}$ is desired, namely $\left(\Phi_{g+} / \Phi_{g-}\right)=4$. Naturally, $\left(\Phi_{g+} / \Phi_{g 0}\right)=2$ and $\left(\Phi_{g-} / \Phi_{g 0}\right)=1 / 2$ are selected. Hence, the variations of $\left(F_{\mathrm{dc}+} / F_{\mathrm{PM}}\right)$ and $\left(F_{\mathrm{dc}-} / F_{\mathrm{PM}}\right)$, with respect to $\left(R_{\mathrm{PM}} / R_{b}\right)$, can be deduced as listed in Table I. When selecting $\left(R_{\mathrm{PM}} / R_{b}\right)=3$, it yields $\left(F_{\mathrm{dc}+} / F_{\mathrm{PM}}\right)=1 / 4$ and $\left(F_{\mathrm{dc}-} / F_{\mathrm{PM}}\right)=1 / 8$. It indicates that a small change in $F_{\mathrm{dc}}$, namely, $25 \%$ of $F_{\mathrm{PM}}$ for flux strengthening and $12.5 \%$ of $F_{\mathrm{PM}}$ for flux weakening, can bring a quadruple variation of $\Phi_{g}$. Therefore, controllable air-gap flux and, hence, constant voltage output can be effectively achieved by regulating the dc field current.

\section{Finite Element Analysis}

Since the machine structure is unusual, its magnetic field distribution and steady-state performance are analyzed by using the FEM. Taking into account both the nonlinear characteristics of the iron core and the PMs, the magnetic field equation of the machine is expressed as

$$
\frac{\partial}{\partial x}\left(v \frac{\partial A_{z}}{\partial x}\right)+\frac{\partial}{\partial y}\left(v \frac{\partial A_{z}}{\partial y}\right)=-J_{z}-J_{\mathrm{pm}}
$$

where $A_{z}$ and $J_{z}$ are the $z$ components of vector magnetic potential $A$ and current density $J$, respectively, $J_{\mathrm{pm}}$ is the equivalent surface current density of PMs, and $v$ is the reluctivity. The corresponding boundary conditions are given by $\left.A\right|_{T_{1}}=$ $\left.A\right|_{T_{2}}=0$ and $\left.A\right|_{N_{1}}=\left.A\right|_{N_{2}}$, where $T_{1}$ and $T_{2}$ are the circumferential boundaries, and $N_{1}$ and $N_{2}$ are the radial boundaries. Due to the periodic machine configuration, the region of interests for finite element analysis is one half of the whole machine cross section.

The field distributions of the proposed machine under no flux control ( $F_{\mathrm{dc}}=0$ A-turns), flux strengthening $\left(F_{\mathrm{dc}+}=+600\right.$ A-turns) and flux weakening ( $F_{\mathrm{dc}-}=-300 \mathrm{~A}$-turns) are shown in Fig. 2, respectively. It can be shown that both flux strengthening and flux weakening can be achieved by controlling the dc field current. Particularly, as shown in Fig. 2(c), the air-bridge

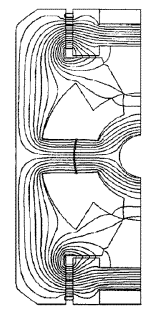

(a)

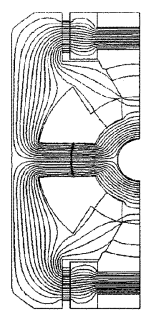

(b)

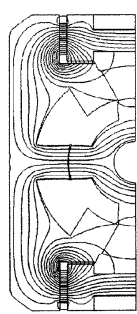

(c)
Fig. 2. Magnetic field distributions under different dc field excitations. (a) 0 A-turns. (b) +600 A-turns. (c) -300 A-turns.

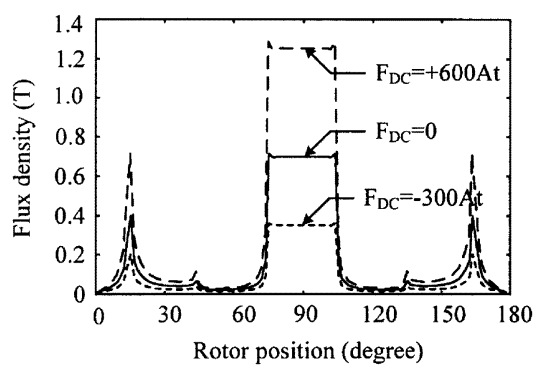

Fig. 3. Air-gap flux density distributions under different dc field excitations.

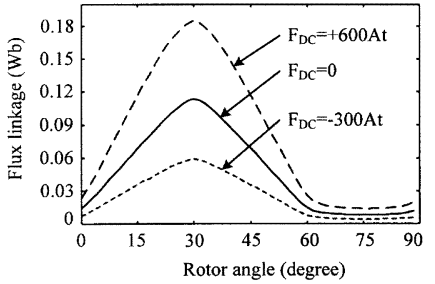

(a)

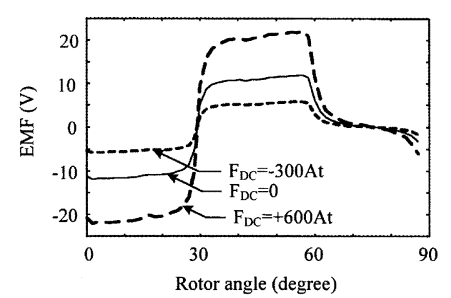

(b)
Fig. 4. Steady-state characteristics under different dc field excitations. (a) Flux linkage. (b) No-load EMF.

flux path can significantly favor the PM flux leakage, hence, amplifying the effect of flux weakening. The corresponding air-gap flux density distributions are shown in Fig. 3. It can be shown that the air-gap flux density can be regulated by about four times. Moreover, the flux linkage and, hence, the no-load EMF under different dc field excitations are deduced as shown in Fig. 4(a) and (b), respectively. It can be shown that the magnitude of the no-load EMF under flux strengthening of +600 A-turns is about four times that under flux weakening of $-300 \mathrm{~A}$-turns. Thus, the results obtained from FEM agree well with those from magnetic circuit analysis.

\section{RESUlTS AND VERIFICATION}

In order to experimentally verify the proposed generator, a prototype was designed and constructed as shown in Fig. 5. This prototype is purposely designed for a standalone $14-\mathrm{V}$ battery-based power system in which both wind generator and photovoltaic modules are installed [4]. The machine specifications and key parameters are listed in Table II.

Fig. 6 shows the measured no-load EMF waveforms at different speeds, namely 300, 600, and $1200 \mathrm{rpm}$, without flux control. It can be shown that both the magnitude and frequency of the EMF waveform at $1200 \mathrm{rpm}$ are about four times those at 


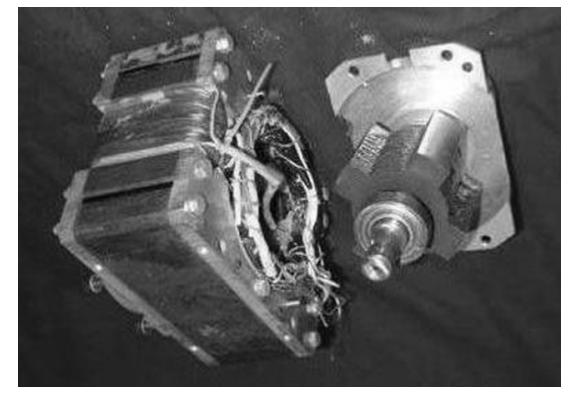

Fig. 5. Machine prototype.

TABLE II

MACHINE SPECIFICATIONS

\begin{tabular}{ll}
\hline Rated DC-link voltage & $14 \mathrm{~V}$ \\
Rated speed & $600 \mathrm{rpm}$ \\
Maximum speed & $1200 \mathrm{rpm}$ \\
Minimum speed & $300 \mathrm{rpm}$ \\
Number of phases & 3 \\
Number of stator poles & 6 \\
Number of rotor poles & 4 \\
Turns per phase & $2 \times 64$ turns \\
Turns of field winding & $2 \times 350$ turns \\
Stator dimensions & $180 \times 145 \times 60 \mathrm{~mm}$ \\
Stator inside diameter & $81.2 \mathrm{~mm}$ \\
Rotor outside diameter & $80.0 \mathrm{~mm}$ \\
Shaft diameter & $20.0 \mathrm{~mm}$ \\
PM material & Sintered Nd-Fe-B \\
Thickness of PM & $3.0 \mathrm{~mm}$ \\
Width of air-bridge & $1.0 \mathrm{~mm}$ \\
\hline
\end{tabular}

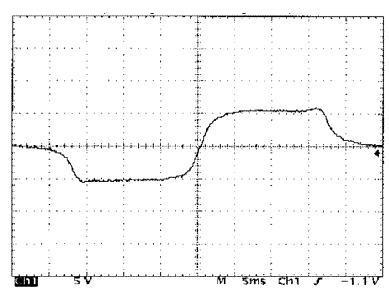

(a)

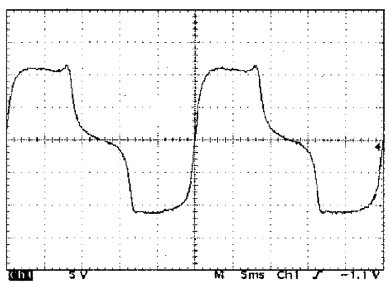

(b)

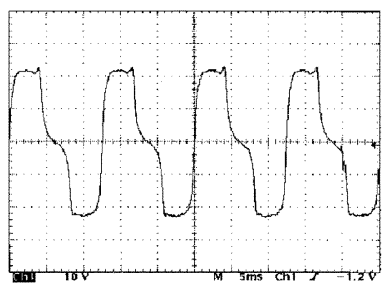

(c)
Fig. 6. Measured output voltage waveforms without flux control. (a) $300 \mathrm{rpm}$ (5 V/div, $5 \mathrm{~ms} / \mathrm{div})$. (b) $600 \mathrm{rpm}$ (5 V/div, $5 \mathrm{~ms} / \mathrm{div})$. (c) $1200 \mathrm{rpm}$ (10 V/div, $5 \mathrm{~ms} / \mathrm{div})$.

$300 \mathrm{rpm}$. Thus, the measured results agree well with the theoretical prediction by magnetic circuit analysis and the FEM results as shown in Fig. 4(b).

In order to prolong the battery life of the standalone power system, it is necessary to maintain constant generator output voltage. To experimentally verify that the capability of online voltage regulation of the proposed machine, the dc field winding current controller is implemented as depicted in Fig. 7. With the use of flux control, the measured output voltage waveforms at a high speed of $1000 \mathrm{rpm}$ under flux weakening of -297 A-turns and at a low speed of $300 \mathrm{rpm}$ under flux strengthening of +595 A-turns are shown in Fig. 8(a) and (b), respectively. It can be

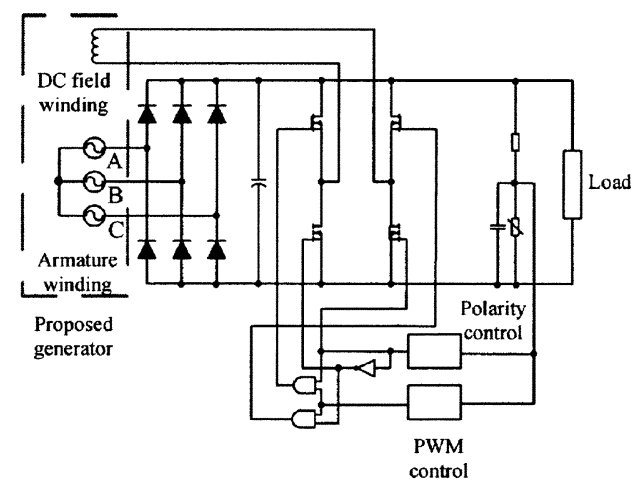

Fig. 7. Schematic of field controller.

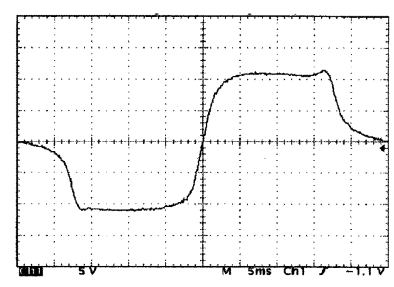

(a)

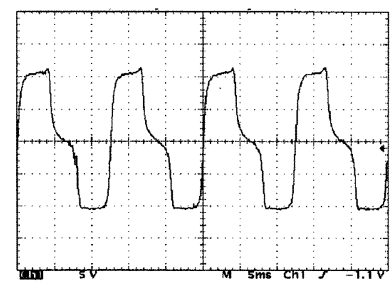

(b)
Fig. 8. Measured output voltage waveforms with flux control. (a) $300 \mathrm{rpm}$ (5 V/div, $5 \mathrm{~ms} / \mathrm{div}$ ). (b) $1000 \mathrm{rpm}(5 \mathrm{~V} / \mathrm{div}, 5 \mathrm{~ms} / \mathrm{div})$.

seen that the magnitudes of the output voltage are almost constant, and also agree well with the results obtained from FEM.

\section{CONCLUSION}

In this paper, a new PM brushless hybrid generator has been proposed, analyzed, and implemented. The key is to newly incorporate a small dc field winding in series with each PM and an air bridge in shunt with each PM in such a way that the air-gap flux can be effectively controlled. Both magnetic circuit and finite element analyzes as well as experimental results, have confirmed that the proposed generator can maintain the output voltage constant under different wind speeds. Although the generator has been exemplified only for a standalone low-voltage battery-based power system, it can readily be applied to a largescale wind power system.

\section{ACKNOWLEDGMENT}

This work was supported by the Research Grants Council, Hong Kong, China under Project HKU 7111/05E.

\section{REFERENCES}

[1] Y. Fan, K. T. Chau, and M. Cheng, "A new three-phase doubly salient permanent magnet machine for wind power generation," IEEE Trans. Ind. Appl., vol. 42, no. 1, pp. 53-60, Jan./Feb. 2006.

[2] K. T. Chau, J. Z. Jiang, and Y. Wang, "A novel stator doubly fed doubly salient permanent magnet brushless machine," IEEE Trans. Magn., vol. 39, no. 5, pp. 3001-3003, Sep. 2003.

[3] M. Cheng, Y. Fan, and K. T. Chau, "Design and analysis of a novel stator-doubly-fed doubly salient motor for electric vehicles," J. Appl. Phys., vol. 97, no. 10, pp. 1-3, Oct. 2005. Paper no. 10Q508.

[4] S. Hashimoto, T. Yachi, and T. Tani, "A new stand-alone hybrid power system with wind generator and photovoltaic modules for a radio base station," in Proc. Int. Telecommun. Energy Conf., 2004, pp. 254-259.

Manuscript received March 13, 2005 (e-mail: sxniu@eee.hku.hk). 